El señor Pestalozzi gozará, a partir de enero de 1977, de un retiro, por tiempo indeterminado, concedido por el Departamento Político Federal y, además de miembro del CICR, será, desde el mes de febrero próximo, asistente especial del presidente del CICR, señor Alexandre Hay, función que desempeñará, con horario de jornada completa, en la sede del CICR.

El CICR se felicita de este nombramiento y de contar en breve con la valiosa colaboración del señor Pestalozzi.

\title{
Prueba de gratitud
}

Hubo, el 16 de diciembre pasado en la sede del CICR, un acto en el transcurso del cual el Comité Internacional expresó su gratitud a tres de sus colaboradores.

Al señor Jean-Pierre Maunoir y a la señora Rose Parmelin, el CICR asignó su medalla de plata por treinta años de actividad al servicio de la Institución; el señor Joseph Abramiec recibió la bandeja de plata del CICR por veinte años de actividad. Hizo entrega de estas pruebas de gratitud el señor A. Hay, presidente del CICR.

En su nombre y en el de sus colegas, el señor J.-P. Maunoir agradeció al CICR la distincción otorgada.

\section{Fallecimiento de la señorita P. Y. Tombet, directora en el CICR}

Al Comité Internacional causa profunda pena el fallecimiento el 15 de diciembre, tras breve enfermedad, de la señorita Paulette Y. Tombet, miembro de la dirección del CICR y directora de la Agencia Central de Informaciones.

La señorita Tombet desempeñaba funciones en el CICR desde diciembre de 1940, habiendo entrado como empleada del Servicio Francés en la Agencia Central de Prisioneros de Guerra. En 1947, fue nombrada jefe de la Secretaría del Servicio Francés y, en 1951, jefe del Servicio Húngaro. En 1957, fue promovida a jefe adjunto de la Dirección de la Agencia. Al mismo tiempo que desempeñaba esas funciones, tuvo a su cargo, a partir de 1964, la Secretaría de la Presidencia del CICR y la Dirección 